\title{
Calcium Activates SK Channels in the Intact Human Lens
}

\author{
Jeremy D. Rhodes, David J. Collison, and George Duncan
}

Purpose. Apamin-sensitive, calcium-activated SK potassium channels have been implicated in schizophrenia and myotonic dystrophy (MD), and both conditions carry an increased risk of cataract. The presence and functional activity of SK channels were therefore investigated in the human lens.

Methods. The expression of all three members of the SK channel family was quantified by PCR. Their functional activity was investigated by using electrophysiological and calciumimaging techniques. Lens voltage was monitored by inserting a single electrode into the intact human lens, and changes in intracellular calcium were recorded simultaneously after fura-2 incorporation.

Results. Expression of all three SK family members was detected in both anterior and equatorial lens epithelial cells. Application of either G-protein (e.g., adenosine triphosphate [ATP]) or tyrosine kinase (EGF) receptor agonists induced a hyperpolarization of lens voltage that was accompanied by an increase in intracellular calcium. The calcium ionophore ionomycin also induced a rapid hyperpolarization. The hyperpolarizing responses were abolished by apamin and trifluoperazine and were accentuated by the SK channel activator 1-ethyl-2benzimidazolinone (1-EBIO).

Conclusions. SK channels are an integral part of the G-protein and tyrosine kinase calcium signaling mechanisms in the human lens, and their activation is inhibited by certain antipsychotic drugs. These findings help explain why a change in channel activity, whether by abnormal gene expression or by drug intervention, can lead to cataract. (Invest Ophthalmol Vis Sci. 2003;44:3927-3932) DOI:10.1167/iovs.03-0013

$\mathrm{C}$ ataract is mainly associated with old age in the developed world, but its prevalence can be increased by certain diseases and clinical conditions. For example, myotonic dystrophy (MD) carries a greatly increased risk of cataract, with most carriers showing opacities by age 40 . Indeed, in many individuals the early onset of cataract is the only indication of the disease. ${ }^{1}$ In a study of more than 300 individuals from 9 MD families all affected members above 20 years of age had cataracts. $^{2}$ In the initial stages MD cataract is characterized by white, light-scattering opacities in the outermost regions of the lens. The later stages show evidence of cortical swelling along the suture lines, and this finally progresses to a mature cataract in which, in slit lamp examination, "an iridescent display of scintillating colors" (Ref. 1) can often be seen. Recently, specific changes in the lens epithelium have been identified in

From the School of Biological Sciences, University of East Anglia, Norwich, United Kingdom.

Supported by the National Lottery Charity Board, United Kingdom, and the Humane Research Trust, United Kingdom.

Submitted for publication January 6, 2003; revised February 6, 2003; accepted March 3, 2003.

Disclosure: J.D. Rhodes, None; D.J. Collison, None; G. Duncan, None

The publication costs of this article were defrayed in part by page charge payment. This article must therefore be marked "advertisement" in accordance with 18 U.S.C. $\$ 1734$ solely to indicate this fact.

Corresponding author: Jeremy D. Rhodes, School of Biological Sciences, University of East Anglia, Norwich NR4 7TJ, UK;

j.rhodes@uea.ac.uk. patients with MD. ${ }^{3}$ Exposure to a variety of stresses, including radiation, oxidation, and several drug therapies, also accelerates the onset of many forms of cataract. For example, phenothiazine treatment for schizophrenia ${ }^{4}$ carries an increased risk of cataract. There are also some reports that the disease itself may be associated with an increased incidence of cataract. ${ }^{5}$ Although the mechanisms underlying MD and schizophrenia are not completely understood, changes in the genes encoding for the $\mathrm{Ca}^{2+}$-activated SK family of channel proteins are believed to play a role in both conditions. ${ }^{6-9}$ The only $\mathrm{Ca}^{2+}$-activated $\mathrm{K}^{+}$channel type that has been unequivocally identified in the human lens is the large-conductance $\mathrm{Ca}^{2+}$. activated $\mathrm{K}^{+}$(BK) channel, ${ }^{10}$ but no association with cataract development has been made. $\mathrm{K}^{+}$channels in general play an obviously important role in determining the overall membrane potential of the lens, and there has also been one report of the involvement of $\mathrm{K}^{+}$channels (of unspecified type) in controlling lens growth in early chick lens development. ${ }^{11}$ In fact a disturbance of $\mathrm{Ca}^{2+}$ homeostasis itself has long been known to play a critical role in cortical cataract formation. ${ }^{12}$

In the present study, we show that the human lens does indeed possess members of the SK family and that activation of either G-protein or tyrosine kinase (TK) $\mathrm{Ca}^{2+}$ signaling systems produces a hyperpolarization of the membrane potential measured in the intact human lens. This hyperpolarization is abolished by exposure of the lens to apamin and to the phenothiazine derivative trifluoperazine (TFP).

\section{Methods}

\section{Tissues and Reagents}

1-Ethyl-2-benzimidazolinone (1-EBIO) and charybdotoxin were obtained from Tocris Cookson, Ltd. (Northampton, UK). All other chemicals were from Sigma-Aldrich Co. Ltd. (Poole, UK), unless stated otherwise. Human donor eyes were obtained from the East Anglian Eye Bank (Norwich, UK) and used 24 to 48 hours after enucleation. As no donor details, apart from age, sex, and cause of death were released, this research followed the tenets of the Declaration of Helsinki. Donors were between the ages of 50 and 85 years old. The lens was dissected through the anterior of the eye and placed into artificial aqueous humor $(\mathrm{AAH})^{9}$ at $35^{\circ} \mathrm{C}$ before use.

\section{Membrane Potential Recordings}

After dissection, the lenses were placed into an acrylic chamber (1.7 $\mathrm{mL})$ and perifused with $\mathrm{AAH}\left(35^{\circ} \mathrm{C}\right)$ at $1 \mathrm{~mL}$ minute ${ }^{-1}$. AAH has the following composition (mM): $\mathrm{NaCl}, 130 ; \mathrm{KCl}, 5 ; \mathrm{NaHCO}_{3}, 5 ; \mathrm{CaCl}_{2}, 1$; $\mathrm{MgCl}_{2}, 0.5$; glucose, 5; HEPES, $20 ; \mathrm{pH}\left(35^{\circ} \mathrm{C}\right)$ was adjusted to 7.25 with $\mathrm{NaOH}$. Agonists and inhibitors were added to the perifusate. Lens membrane potential $\left(V_{\mathrm{m}}\right)$ was measured as previously described. ${ }^{13,14} \mathrm{~A}$ glass micropipette filled with $2 \mathrm{M} \mathrm{KCl}(1-6 \mathrm{M} \Omega$ ) inserted into a cortical fiber through the posterior of the lens measured $V_{\mathrm{m}}$ with reference to a low-resistance electrode in the bath. Lens cells are electrically very well coupled ${ }^{14,15}$ and so $V_{\mathrm{m}}$ is a measure largely of the voltage across the plasma membrane of the outermost cells. Electrical measurements were recorded with a 2-channel high-impedance amplifier (Firbank Electronics, Norwich, UK) in conjunction with an analogue-to-digital converter (Handyscope; TiePie Engineering, Leeuwarden, The Netherlands) for storage and analysis on computer. 


\section{Intracellular $\mathrm{Ca}^{2+}$ Measurement}

Intracellular $\mathrm{Ca}^{2+}$ levels were monitored using methods that have been described in detail elsewhere. ${ }^{16}$ Briefly, the intact lens was loaded with $3 \mu \mathrm{M}$ fura-2 (fura-2/AM) in AAH for 40 minutes at $35^{\circ} \mathrm{C}$. The lens was washed for a further 20 minutes in $\mathrm{AAH}$ and placed anterior surface downward in an acrylic chamber (Perspex) and perifused with AAH $\left(35^{\circ} \mathrm{C}\right)$. The solution turnover time for the chamber was approximately 10 seconds. Ratiometric imaging of cytosolic $\mathrm{Ca}^{2+}$ was performed on the stage of an epifluorescence microscope (TE-200; Nikon, Tokyo, Japan). Cells were excited alternately with light of 340 and $380 \mathrm{~nm}$ wavelength. The resultant fluorescent emissions were collected by a charge-coupled device (CCD) camera at $510 \mathrm{~nm}$ and sampled every 2 seconds. After background subtraction the fluorescence ratios were recorded. No fluorescence signal was obtained from the lens posterior region or lens nucleus, but stable signals were obtained from the anterior and equatorial cells. Lens voltage was monitored simultaneously by inserting a glass micropipette into a cortical fiber cell through the posterior of the lens, as previously described. Both the resting membrane potential of the lens and the characteristics of the voltage responses appeared to be unaffected by the simultaneous measurement of intracellular calcium and were similar to those recorded in separate experiments in this and other studies. ${ }^{17}$

\section{Quantitative Real-Time PCR}

There are three subtypes of apamin-sensitive $\mathrm{K}^{+}$channel (SK1-3) that have been identified in other human tissues, ${ }^{18}$ and the molecular basis for this diversity has been determined by the cloning of three genes encoding SK channels from mammalian tissue. ${ }^{19}$ We used quantitative real-time PCR molecular techniques to determine which subtypes are present in the lens.

For RNA extraction the lens epithelium was dissected into the anterior and equatorial regions. Total RNA was isolated from each region using a kit (RNEASY with the RNase-free DNase set; Qiagen, Valencia, CA). Two hundred nanograms of RNA were used to make cDNA in a total reaction volume of $20 \mu \mathrm{L}$ with a commercial system (Superscript II RNase $\mathrm{H}^{-}$reverse transcriptase; Invitrogen-Life Technologies, Rockville, MD). PCR (TaqMan) was performed with a sequence-detection system (Prism 7700; Applied Biosystems, Foster City, CA) to identify and quantify the expression of SK1, SK2, and SK3 channels in the regions of the lens, according to the manufacturer's protocol. Each reaction was performed in a total volume of $25 \mu \mathrm{L}$ and contained the equivalent of $5 \mathrm{ng}$ human cDNA ( $1 \mathrm{ng}$ for the $18 \mathrm{~S}$ analyses), $50 \% 2 \times$ PCR master mix (TaqMan Master Mix; Applied Biosystems, Inc.), $100 \mathrm{nM}$ each of forward and reverse primer, and 200 $\mathrm{nM}$ probe. Conditions for the PCR reaction were 2 minutes at $50^{\circ} \mathrm{C}$ and 10 minutes at $95^{\circ} \mathrm{C}$, and then 40 cycles, each consisting of 15 seconds at $95^{\circ} \mathrm{C}$ and 1 minute at $60^{\circ} \mathrm{C}$. The primer and probe sequences used (TaqMan; Applied Biosystems, Inc.) were those described by Rimini et al., ${ }^{20}$ and were designed from human sequences for SK1, SK2, and SK3. Probes were FAM labeled at their $5^{\prime}$ end. Data were analyzed using the software provided (TaqMan, Applied Biosystems, Inc.). $\mathrm{C}_{\mathrm{t}}$ values were converted to arbitrary units, and differences between the samples were normalized with $18 \mathrm{~S}$ mRNA by having a standard curve on each plate. Absolute quantification is possible if the standard curve uses a synthetic RNA corresponding to the target gene; however, in this case the standard was based on total RNA from lens epithelium and so the analysis provided only relative quantification.

\section{Capsular Bags}

To elucidate any possible effect of apamin inhibition on the expression of SK channels in human lens cells, we used the capsular bag system developed in this laboratory. ${ }^{21} \mathrm{~A}$ sham cataract operation was performed on donor lenses, and the resultant capsular bag was then dissected from the zonules and secured to a plastic Petri dish by pins that retained its original circular shape. The capsular bags were maintained in a nonsupplemented (serum-free; SF) Eagle's minimum essential medium (EMEM) at $35^{\circ} \mathrm{C}$ in a $5 \% \mathrm{CO}_{2}$ atmosphere. The medium was replaced at 4-day intervals. Previous work from this laboratory has shown that native lens cells residing on their original capsular matrix continue to grow over long periods in SF medium. ${ }^{22}$ Experiments were performed in a matched-pair format in which apamin was added to the medium of the capsular bag from one lens while the corresponding bag from the same donor served as the control. When epithelial cells had completely covered the posterior capsule ( $\sim 10-15$ days) RNA was extracted and PCR performed as described earlier.

\section{RESUlts}

\section{Changes in Lens Voltage in Response to $\mathrm{Ca}^{2+}$-Mobilizing Agonists}

The lens represents a well-coupled electrical syncytium, so that the voltage measured at any point in the lens monitors the net effect of channel activity, largely in the membranes of the surface epithelium and superficial fibers. ${ }^{14,15,23}$ Exposure to $100 \mu \mathrm{M}$ adenosine triphosphate (ATP) induced an initial hyperpolarization, ranging from 0.5 to $4 \mathrm{mV}$ in amplitude $(n=$ $10)$, and this was followed by a more prolonged depolarization phase (Fig. 1A). On some occasions, small oscillations were apparent in the hyperpolarization phase of the response (see Figs. 1A, 2B). The same two phases in the response were also apparent when the lens was exposed to epidermal growth factor (EGF; $10 \mathrm{ng} / \mathrm{mL}$; Fig. 1B), although the initial hyperpolarization was less rapid and much smaller in amplitude (0.1-

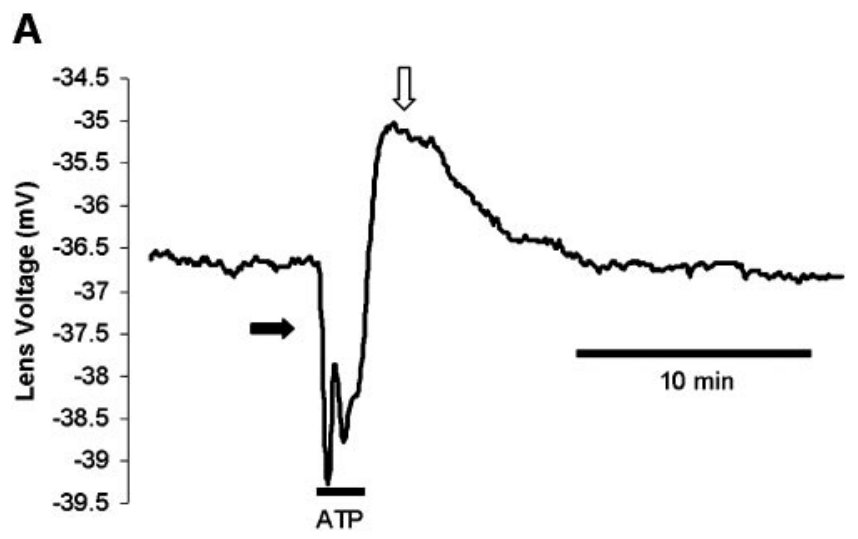

B

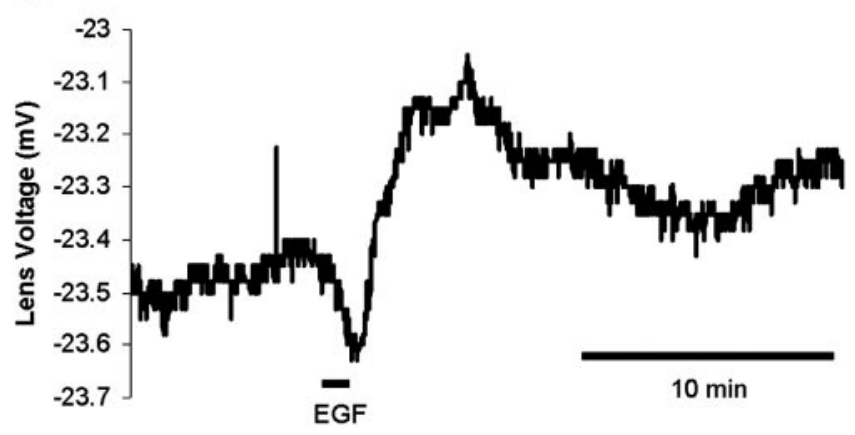

Figure 1. Voltage response of the lens after exposure to a G-proteincoupled receptor agonist (ATP) and a tyrosine kinase receptor agonist (EGF). (A) A brief exposure ( 2 minutes) to ATP $(100 \mu \mathrm{M})$ produced a rapid hyperpolarization (filled arrow) which was followed by a pronounced depolarization phase (open arrow). (B) Exposure to EGF (10 $\mathrm{ng} / \mathrm{mL}$ ) resulted in both hyperpolarization and depolarization phases of the voltage response, although the former was smaller and of a slower time course than for G-protein agonists (A). The data shown are representative of responses obtained in several preparations: ATP, $n=$ 10 ; EGF, $n=3$. 
$0.2 \mathrm{mV}, n=3)$. A number of other G-protein coupled receptor (GPCR) agonists (histamine, acetylcholine and uridine triphosphate [UTP]) were also found to induce the hyperpolarization phase and their amplitudes of response and time course were similar to those found with ATP. Note that not only were the responses to the various agonists reproducible in different preparations but subsequent applications on the same preparation gave similar responses providing sufficient time $(t>15$ minutes) was allowed between applications.

Recently, techniques have been developed to measure intracellular $\mathrm{Ca}^{2+}$ changes in the intact lens using the fluorometric reporter dye fura-2. ${ }^{16}$ Figure $2 \mathrm{~A}$ shows intracellular $\mathrm{Ca}^{2+}$ and lens voltage data obtained simultaneously from the same lens, and in this case, the fura- 2 signals, in response to histamine $(100 \mu \mathrm{M})$, were recorded from equatorial epithelial cells of an intact lens. Histamine induces a typical biphasic voltage response, whereas the $\mathrm{Ca}^{2+}$ response shown is monotonic in form, which was typical of all the GPCR agonists used. However, a second phase is in fact embedded in the $\mathrm{Ca}^{2+}$ signal, because the $\mathrm{Ca}^{2+}$ influx blocking agent $\mathrm{La}^{3+}$ greatly reduced

\section{A}
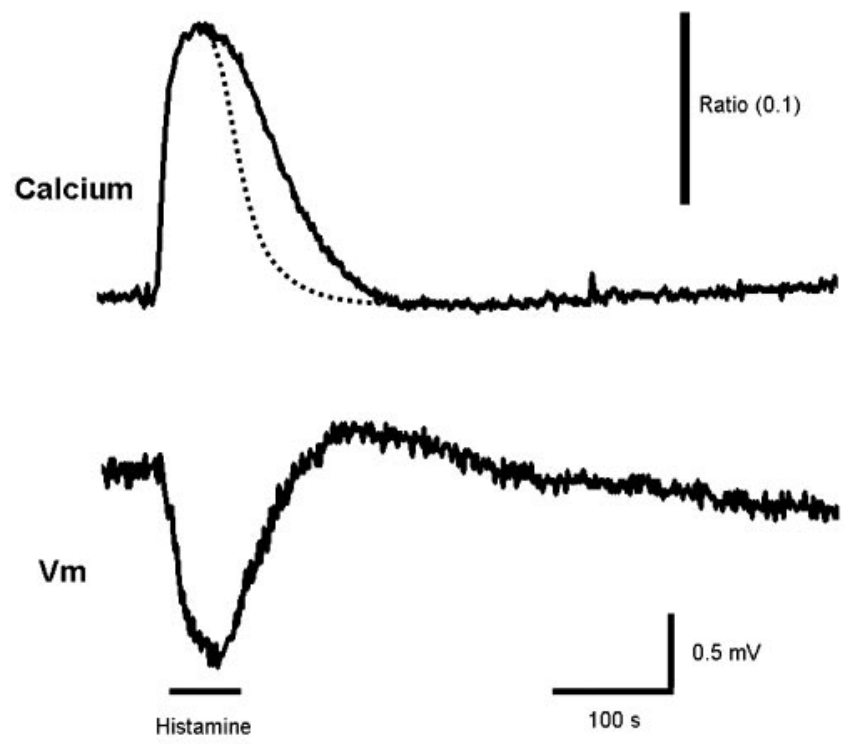

B

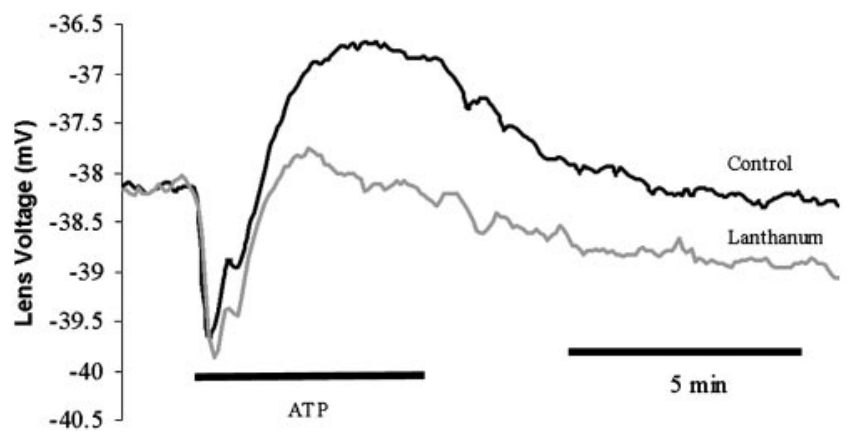

Figure 2. Origin of the two phases of the voltage response. (A) Time course of the fura-2-monitored intracellular $\mathrm{Ca}^{2+}$ increase (top trace) and the biphasic voltage response (bottom trace) to histamine (100 $\mu \mathrm{M})$ measured simultaneously in a perifused human lens. The intracellular $\mathrm{Ca}^{2+}$ response was recorded from the equatorial region of the lens. In the top trace the dashed curve shows the response in the presence of $\mathrm{La}^{3+}(10 \mu \mathrm{M})$, which blocked the $\mathrm{Ca}^{2+}$ entry pathway. Note that an increase in fluorescence ratio represents an increase in cytosolic $\mathrm{Ca}^{2+}$. (B) Voltage responses to ATP $(100 \mu \mathrm{M})$ in control AAH and in the presence of $\mathrm{La}^{3+}(10 \mu \mathrm{M})$.

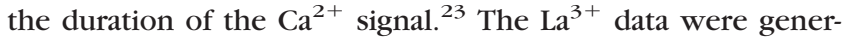
ated in a separate series of experiments and are shown in Figure 2A (dashed line). Note that $\mathrm{La}^{3+}$ had no effect on the rising phase of the $\mathrm{Ca}^{2+}$ response, which is due to a rapid release of $\mathrm{Ca}^{2+}$ from inositol-trisphosphate-sensitive stores. ${ }^{24}$ Exposure to $\mathrm{La}^{3+}$ had no effect on the initial hyperpolarization but greatly reduced the depolarization phase of the response (Fig. 2B). The increase in intracellular $\mathrm{Ca}^{2+}$ in response to EGF was significantly slower than for the GPCR agonists (data not shown) and this was reflected in the dynamics of the hyperpolarization (Fig. 1B). Another study has also shown that the $\mathrm{Ca}^{2+}$ response to EGF is smaller in magnitude than that induced by GPCR agonists, such as ATP. ${ }^{16}$

\section{Selective Inhibition-Activation of the Voltage Response}

A series of selective $\mathrm{K}^{+}$channel inhibitors were applied to the lens to assess their ability to inhibit the hyperpolarization phase of the response. The SK-specific inhibitor apamin totally abolished the hyperpolarization at nanomolar concentrations ( $\mathrm{IC}_{50} 600 \mathrm{pM}$; data not shown) and had no inhibitory effect on the depolarization. In fact, the depolarization phase of the response was slightly larger in the presence of apamin (Fig. 3A). When apamin was removed, the hyperpolarization phase gradually recovered on subsequent exposure to ATP (Fig. 3A) and the rate of recovery depended greatly on the apamin concentration. Note that apamin had no effect on the unstimulated membrane potential of the lens. Charybdotoxin $(100 \mathrm{nM})$ had no effect on the voltage response (data not shown).

1 -EBIO is an activator of SK channel activity, ${ }^{25}$ and in the human lens greatly accentuated the hyperpolarization phase of the ATP response without increasing the depolarization phase (Fig. 3B). The hyperpolarization in the presence of 1-EBIO was also blocked by apamin (data not shown).

\section{Hyperpolarization Phase Specifically Induced by $\mathrm{Ca}^{2+}$}

Some GPCR agonist responses are due in part to a specific interaction of the agonist with a membrane channel ${ }^{26}$ and so it was important to show in the lens whether an increase in intracellular $\mathrm{Ca}^{2+}$ alone could induce a hyperpolarization in the membrane voltage. This was indeed found to be the case, because ionomycin, a $\mathrm{Ca}^{2+}$ ionophore, induced a marked hyperpolarization in the presence of $1 \mathrm{mM}$ external $\mathrm{Ca}^{2+}$. In contrast, removing external $\mathrm{Ca}^{2+}$ in the presence of ionomycin depolarized the lens, whereas adding $5 \mathrm{mM}$ external $\mathrm{Ca}^{2+}$ caused a very large reversible hyperpolarization (Fig. 3C). The ionomycin-induced hyperpolarization was blocked by apamin (data not shown). Note that although ionomycin remained in the bath for only approximately 5 minutes, it rapidly and irreversibly incorporated into membranes and is in fact used as a means of equilibrating internal and external $\mathrm{Ca}^{2+}$ levels in lens cells and a range of other tissues. ${ }^{24}$

In the intact human lens prior exposure to TFP $(100 \mu \mathrm{M})$ totally abolished the large ionomycin-induced hyperpolarization (Fig. 3D). TFP also blocked the hyperpolarization induced by ATP (data not shown).

\section{Quantitative Real-Time PCR Analysis of SK Channel Expression}

The data in Figure 4A show that, although all three SK channel family members were present in the lens, they were not uniformly distributed between the two cell types. In general, they were more abundant in the anterior epithelial cells than they are in the equatorial cells. The asymmetry in distribution is most pronounced for SK1 (Fig. 4A) which showed between 
A

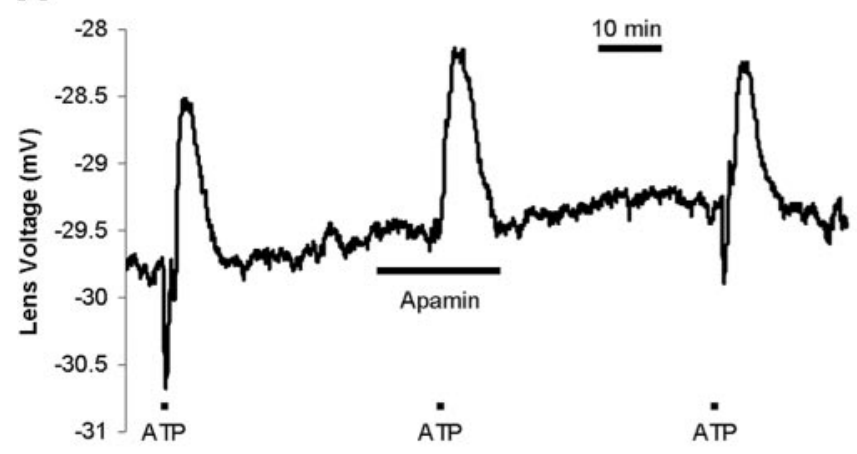

B

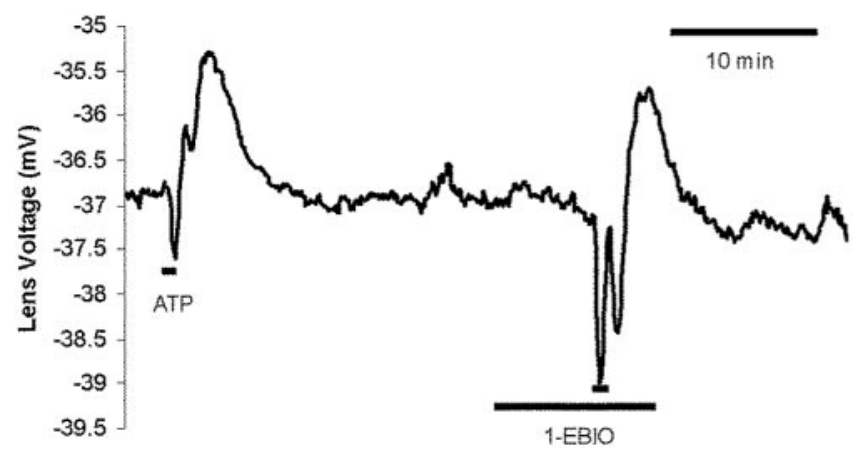

C

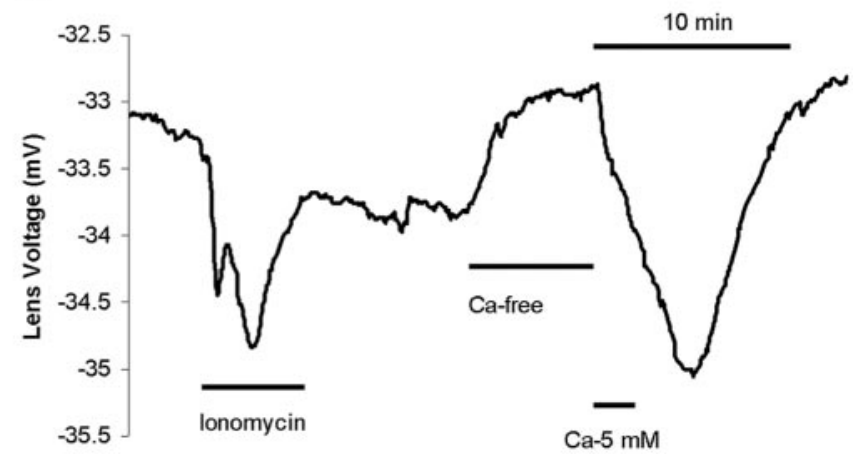

D

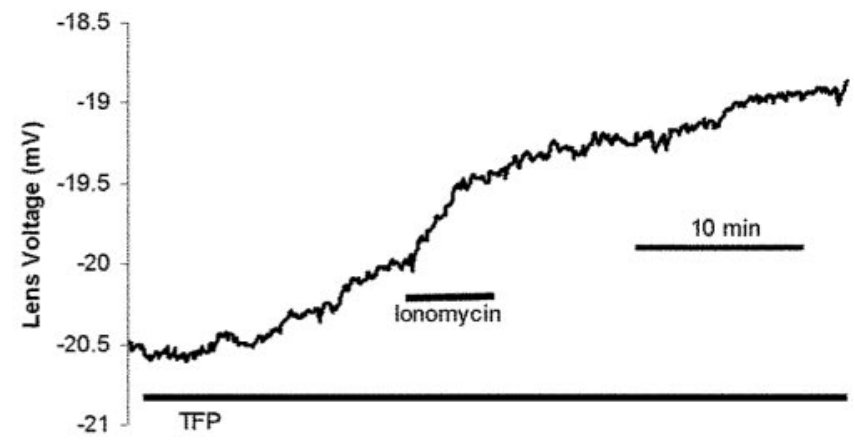

FigURE 3. Sensitivity of the lens voltage response to channel activators and inhibitors. (A) ATP (100 $\mu \mathrm{M})$ induced hyperpolarization is reversibly inhibited by apamin $(10 \mathrm{nM})$. (B) The voltage response to ATP $(100 \mu \mathrm{M})$ was markedly increased in the presence of the $\mathrm{K}_{\mathrm{Ca}}$ activator 1-EBIO (100

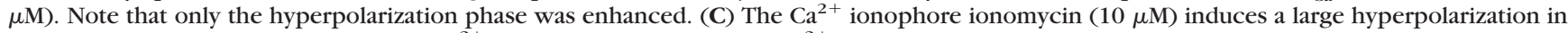
the lens voltage in control AAH $\left(1 \mathrm{mM} \mathrm{Ca}^{2+}\right)$. Exposure to a nominally $\mathrm{Ca}^{2+}$-free solution $(\sim 1 \mu \mathrm{M})$ induced a depolarization, whereas increasing external $\mathrm{Ca}^{2+}$ to $5 \mathrm{mM}$ induced a large and reversible hyperpolarization. (D) Exposure to ionomycin (10 $\left.\mu \mathrm{M}\right)$ in the presence of TFP (100 $\left.\mu \mathrm{M}\right)$ abolished the hyperpolarization phase of the response $(\mathbf{C})$.

3.7- and 11-fold greater expression in the anterior epithelium than the equatorial cells $(n=3)$. The three SK family members were also found to be expressed in the human lens cell line FHL-124 (data not shown).

\section{Apamin-Induced Changes in Channel Expression}

The human lens capsular bag provides a convenient means of culturing lens cells on their natural matrix where cells continue to grow for many weeks under SF conditions. ${ }^{27}$ Exposure to apamin $(1 \mu \mathrm{M})$ induced an upregulation in the expression of SK1 and SK3 relative to control in every case $(n=4)$, but there appeared to be little effect on the expression of SK2 (Fig. 4B). Visually, exposure to apamin ( $>7$ days) appeared to have little effect on the capsular bags apart from a small growth retardation, relative to the match-paired control.

\section{Discussion}

The $\mathrm{Ca}^{2+}$-activated $\mathrm{K}^{+}$channel family exists as a heterogeneous association of three subfamilies: BK, IK, and SK channels. ${ }^{18}$ The large-conductance $\mathrm{Ca}^{2+}$-activated $\mathrm{K}^{+}$(BK) channels are characterized by having a large unit conductance $(\sim 250 \mathrm{pS})$ which is activated by both voltage and $\mathrm{Ca}^{2+}$ and blocked by charybdotoxin and iberiotoxin. The voltage-independent intermediate conductance (IK) channel subfamily has unit conductance in the range of 20 to $80 \mathrm{pS}$ and is sensitive to block by charybdotoxin. The gating of small-conductance $\mathrm{Ca}^{2+}$-activated $\mathrm{K}^{+}$(SK) channels by $\mathrm{Ca}^{2+}$ is mediated by calmodulin, which is stably bound as an obligatory subunit of the channel complex. ${ }^{28}$ IK channels share related amino acid sequences with the SK channels and also use calmodulin binding to confer their $\mathrm{Ca}^{2+}$ sensitivity. ${ }^{29}$ SK channels have a unit conductance in the range of 4 to $14 \mathrm{pS}$ and are also voltage independent. They are insensitive to charybdotoxin but sensitive to apamin. They are activated by submicromolar intracellular $\mathrm{Ca}^{2+}$ concentrations with a half-maximum activation in the range of 400 to $800 \mathrm{nM}$ in neuronal cells. The calibrated $\mathrm{Ca}^{2+}$ changes in the epithelial cells of the whole lens after GPCR activation indicate that the $\mathrm{Ca}^{2+}$ increased from $\sim 100$ $\mathrm{nM}$ to $\sim 1 \mu \mathrm{M} .{ }^{16}$ This $\mathrm{Ca}^{2+}$ increase occurred at precisely the time that lens membrane hyperpolarization occurs (Fig. 3A), indicating that the two processes are closely linked. In neurons there is an apamin-sensitive after-hyperpolarization (AH) that also parallels the increase and decrease in $\mathrm{Ca}^{2+}$. In our study, hyperpolarization in the lens was induced by an increase in intracellular $\mathrm{Ca}^{2+}$, whatever the source (Fig. 3C).

Because the voltage response represents the net activity of all the channels in the lens, it is important that a change in perifusate be experienced by all surface receptors at the same time. This is especially true for a response that has both hyperpolarizing and depolarizing phases. Previous studies on the human lens have focused on the depolarizing phase of the response, ${ }^{17,30}$ and we have found that a relatively rapid perfusion is required to reveal the full extent of the hyperpolarization.

The depolarization phase of the normal voltage response undoubtedly arises from the activity of the store-operated or capacitative $\mathrm{Ca}^{2+}$ entry pathway (Fig. 1), as this phase is 
A

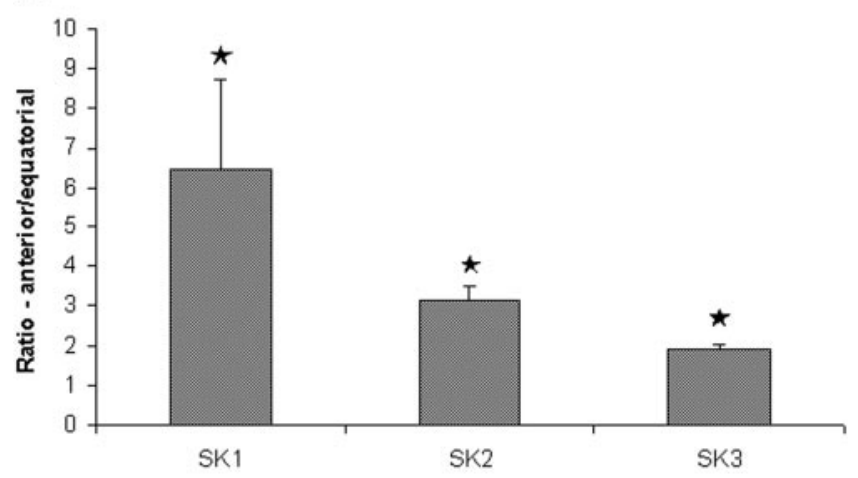

B

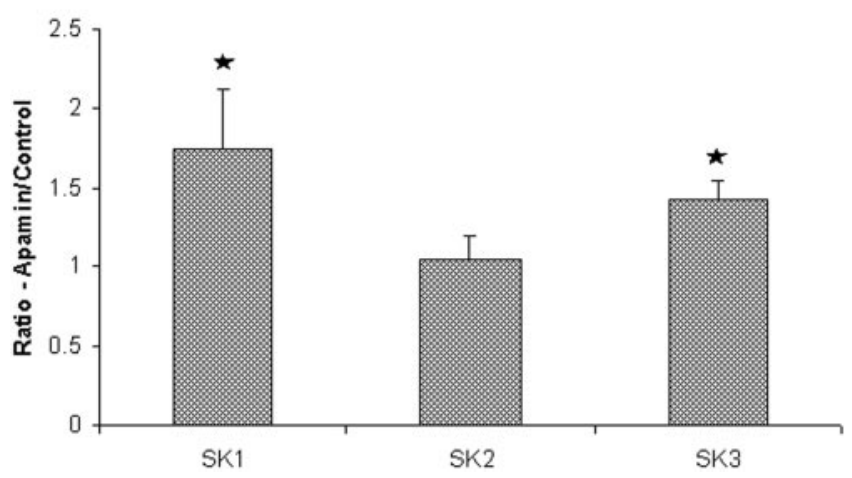

FIgURE 4. Quantitative RT-PCR showing (A) the relative abundance of the three SK family members in the anterior and equatorial epithelial cells and (B) the stimulation in expression level obtained after apamin exposure for 7 days. ${ }^{*}$ Significant difference from 1 ( $\left.P \leq 0.05\right)$. $n \geq 3$ in all cases.

blocked by $\mathrm{La}^{3+} \cdot{ }^{23}$ It is interesting in the lens that the entry pathway is only activated after a significant delay. ${ }^{16,23,24}$ The delay allows for a separation in time between the increase in intracellular $\mathrm{Ca}^{2+}$ due to release from the $\mathrm{Ca}^{2+}$ stores and the subsequent depolarization due to the opening of the $\mathrm{Ca}^{2+}$ entry pathway. This in turn allows for the rapid initial hyperpolarization to be quite separate from the later depolarization, and this separation would not occur in those cell types where there is no, or only a very brief, delay between $\mathrm{Ca}^{2+}$ release and $\mathrm{Ca}^{2+}$ entry. In the present study the hyperpolarization was unaffected by $\mathrm{La}^{3+}$, confirming that it is caused by the rapid release of $\mathrm{Ca}^{2+}$ from intracellular stores.

In the human lens, the hyperpolarization was totally inhibited by nanomolar concentrations of apamin, indicating that neither BK nor IK channels mediated the response. Furthermore, the hyperpolarization was insensitive to charybdotoxin. Because neither apamin nor 1-EBIO induced a change in the unstimulated lens membrane potential, it is likely that SK channels do not contribute to the steady state resting potential of the lens. This also appears to be the case in neuronal tissue in which apamin sensitivity is seen only during the AH phase. ${ }^{18}$ Additional pharmacological evidence that SK channels are responsible for the hyperpolarization phase of the response was shown by the potentiating effect of 1-EBIO on the hyperpolarization (Fig. 3B). 1-EBIO can activate both IK and SK channels by increasing the channel open probability without affecting the affinity for $\mathrm{Ca}^{2+}$ although activation is strictly $\mathrm{Ca}^{2+}$ dependent. ${ }^{25,31}$ In the lens the enhanced hyperpolarization in the presence of 1-EBIO was blocked by apamin, confirming that it acted on SK and not IK channels.
The GPCRs for ATP and histamine are present in both anterior and equatorial epithelial cells, whereas acetylcholine receptors are present only in the anterior epithelium. In contrast, EGF stimulates only the equatorial cells. ${ }^{16}$ Because both acetylcholine and EGF induce hyperpolarizations in the whole lens, it is possible to conclude that, both anterior and equatorial epithelial cells can contribute to the hyperpolarization phase of the response. It is to be expected, however, that activation of GPCRs and tyrosine kinase receptors (TKRs) will not contribute equally to the overall voltage response for a number of reasons. TKR agonists (e.g., EGF and platelet-derived growth factor [PDGF]) only initiate $\mathrm{Ca}^{2+}$ responses in equatorial cells, ${ }^{16}$ and this represents only a small subpopulation of the total epithelial cells. Furthermore, the TK $\mathrm{Ca}^{2+}$ response from equatorial cells is slower in time course and smaller in amplitude than the corresponding GPCR responses (see Ref. 16 for discussion). Because of the slow nature of the TKR response the $\mathrm{Ca}^{2+}$ release and capacitative entry phases are not separated in time with the same clarity as the GPCR responses, and so the overall voltage response, even in the initial stages, contains both hyperpolarizing and depolarizing phases. Because the superficial fiber cells do not appear to accumulate fura-2, it is not possible to assess any potential contribution from this source. However, in the double-chamber system used to isolate voltage responses in the rabbit lens to acetylcholine, there was no response from the posterior fibers. ${ }^{32}$ The posterior fibers certainly contain $\mathrm{K}^{+}$channels, but because most have lost their endoplasmic reticulum it is unlikely that agonist-induced $\mathrm{Ca}^{2+}$ signals can be induced in this population.

An indication of the importance of SK channel activity to the lens is shown by the fact that all three family members were found to be present in the same cell type (Fig. $4 \mathrm{~A}$ ). The SK1 channel subtype is widely regarded as being relatively apamin insensitive, ${ }^{18}$ and the accepted order of sensitivity to apamin is, SK2 $>$ SK3 $>$ SK1. The IC $_{50}$ for the apamin inhibition of the hyperpolarization produced in response to ATP was $600 \mathrm{pM}$ (data not shown) and it is not possible on this basis alone to say which of the subtypes contributed most to the hyperpolarization.

There is intriguing evidence that SK3 channels may play a role in MD. The muscles of patients with MD, for example, show a marked increase in apamin binding, which does not occur in normal skeletal muscle, ${ }^{6}$ and injection of apamin into the muscle of patients with MD reduces the symptoms of myotonia. ${ }^{7}$ Of note, the $\mathrm{K}^{+}$channel inhibitor, quinine, has also been shown to relieve MD symptoms. ${ }^{1}$ We have also found that quinine inhibits the initial hyperpolarizing phase (data not shown). The expression of SK channel mRNA was highest in the anterior epithelium of the lens, and this appears to be a region severely affected in MD where a greatly reduced cell density is observed. ${ }^{3}$ In persons with MD, the cataract is of a cortical rather than nuclear type and the former are generally associated with a loss of control of ion regulation. Loss of $\mathrm{Ca}^{2+}$ control is critical in cortical cataract, because $\mathrm{Ca}^{2+}$-activation of proteases leads to a catastrophic loss of protein from the lens. ${ }^{12}$

Changes in SK channel activity have also been associated with schizophrenia, ${ }^{8,9,33,34}$ and cataract has been attributed both to the disorder and the antipsychotic drug therapy. ${ }^{4}$ Direct exposure to the phenothiazines TFP and chlorpromazine in animal models has been shown to induce cataract ${ }^{35,36}$ and alter the activity of unspecified lens $\mathrm{K}^{+}$channels. ${ }^{37,38}$ It has also been shown that a range of phenothiazine derivatives (including TFP) block SK channels with micromolar activity. They appear to act directly on the SK channels and not by inhibiting calmodulin, because they were able to displace $\left[{ }^{125} \mathrm{I}\right]$ apamin binding, whereas unrelated calmodulin inhibitors have no effect on channel activity. ${ }^{39}$ The present study helps to 
identify SK as the channel type responsible, because a general $\mathrm{Ca}^{2+}$-activated hyperpolarization induced by ionomycin was abolished both by apamin and TFP (Fig. 3D).

SK channel activation should now be seen as an integral part of calcium cell signaling in the lens, and it is possible that they participate in a range of functions. For example, recent studies have shown that SK channel activation occurs after osmotic stress, ${ }^{40,41}$ and lens swelling is one characteristic of cortical cataract. ${ }^{42}$ It is interesting that there was an upregulation in the expression of SK1 and SK3 mRNA in cells grown in the presence of apamin (Fig. 4B), suggesting a dynamic role for these channels in the lens.

\section{Acknowledgments}

The authors thank Caroline Pennington for expert technical assistance with the PCR, Dylan Edwards for use of the PCR system, and Lixin Wang for kind assistance in the capsular bag experiments.

\section{References}

1. Duke-Elder S. Diseases of the lens and vitreous. In: Systems of Ophthalmology. Vol. 4. London: H Kimpton; 1969;183-188.

2. Junge J. Ocular changes in dystrophia myotonica. Ophthalmologica. 1968;155:291-293.

3. Abe T, Sato M, Kuboki J, Kano T, Tamai M. Lens epithelial changes and mutated gene expression in patients with myotonic dystrophy. Br J Ophthalmol. 1999;83:452- 457.

4. Isaac NE, Walker AM, Jick H, Gorman M. Exposure to phenothiazine drugs and risk of cataract. Arch Ophthalmol. 1991;109:256-260.

5. McCarty CA, Wood CA, Fu CL, et al. Schizophrenia, psychotropic medication, and cataract. Ophthalmology. 1999;106:683-687.

6. Renaud JF, Desnuelle C, Schmid-Antomarchi H, Hugues M, Serratrice G, Lazdunski M. Expression of apamin receptors in muscle of patients with myotonic muscular dystrophy. Nature. 1986;319: 678-680.

7. Behrens M I, Jalil P, Serani A, Vergara F, Alvarez O. Possible role of apamin-sensitive $\mathrm{K}^{+}$channels in myotonic dystrophy. Muscle Nerve. 1994;17:1264-1270.

8. Chandy KG, Fantino E, Wittekindt $\mathrm{O}$, et al. Isolation of a novel potassium channel gene $b S K C a 3$ containing a polymorphic CAG repeat: a candidate for schizophrenia and bipolar disorder. Mol Psychiatry. 1998;3:32-37.

9. Cardno AG, Bowen T, Guy CA, et al. CAG repeat length in the hKCa3 gene and symptom dimensions in schizophrenia. Biol Psychiatry. 1999;45:1592-1596.

10. Shepard AR, Rae JL. Ion transporters and receptors in cDNA libraries from lens and cornea epithelia. Curr Eye Res. 1998;17: $708-719$.

11. Parmelee JT, Beebe DC. Decreased membrane-permeability to potassium is responsible for the cell-volume increase that drives lens fibre cell elongation. J Cell Physiol. 1988;134:491- 496.

12. Duncan G, Williams MR, Riach RA. Calcium cell signalling and cataract. Prog Retinal Eye Res. 1994;13:623-652.

13. Duncan G, Hightower KR, Gandolfi SA, Tomlinson J, Maraini G. Human lens membrane cation permeability increases with age. Invest Ophthalmol Vis Sci. 1989;30:1855-1859.

14. Duncan G, Patmore L, Pynsent PB. The impedance of the amphibian lens. J Physiol. 1981;312:17-27.

15. Rae JL, Thompson RD, Eisenberg RS. The effect of 2-4 dinitrophenol on cell to cell communication in the frog lens. Exp Eye Res. 1982;35:597-609.

16. Collison DJ, Duncan G. Regional differences in functional receptor distribution and calcium mobilization in the intact lens. Invest Ophthalmol Vis Sci. 2001;42:2355-2363.

17. Rhodes JD, Thomas GR, Duncan G. Acetylcholine-induced electrical responses in intact human, rat and rabbit lenses. Exp Eye Res. 2002;74:417-421.

18. Vergara C, Latorre R, Marrion NV, Adelman JP. Calcium-activated potassium channels. Curr Opin Neurobiol. 1998;8:321-329.
19. Kohler M, Hirschberg B, Bond CT, et al. Small-conductance, calcium-activated potassium channels from mammalian brain. Science. 1996;273:1709-1714.

20. Rimini R, Rimland JM, Terstappen GC. Quantitative expression analysis of the small conductance calcium-activated potassium channels, SK1, SK2 and SK3, in human brain. Mol Brain Res. 2000;85:218-220.

21. Liu CS, Wormstone IM, Duncan G, Marcantonio JM, Webb SF, Davies PD. A study of human lens cell growth in vitro: a model for posterior capsule opacification. Invest Ophthalmol Vis Sci. 1996; 37:906-914.

22. Wormstone IM, Liu CS, Rakic JM, Marcantonio JM, Vrensen GF, Duncan G. Human lens epithelial cell proliferation in a protein-free medium. Invest Ophthalmol Vis Sci. 1997;38:396-404.

23. Thomas GR, Sanderson J, Duncan G. Thapsigargin inhibits a potassium conductance and stimulates calcium influx in the intact rat lens. J Physiol. 1999;516:191-199.

24. Riach RA, Duncan G, Williams MR, Webb SF. Histamine and ATP mobilize calcium by activation of $\mathrm{H}_{1}$ and $\mathrm{P}_{2 \mathrm{U}}$ receptors in human lens epithelial cells. J Physiol. 1995;486:273-282.

25. Syme CA, Gerlach AC, Singh AK, Devor DC. Pharmacological activation of cloned intermediate- and small-conductance $\mathrm{Ca}^{2+}$. activated $\mathrm{K}^{+}$channels. Am J Physiol. 2000;278:C570-C581.

26. Shieh CC, Coghlan M, Sullivan JP, Gopalakrishnan M. Potassium channels: molecular defects, diseases, and therapeutic opportunities. Pharmacol Rev. 2000;52:557-593.

27. Wormstone IM, Tamiya S, Marcantonio JM, Reddan JR. Hepatocyte growth factor function and c-Met expression in human lens epithelial cells. Invest Ophthalmol Vis Sci. 2000;41:4216-4222.

28. Xia X-M, Fakler B, Rivard A, et al. Mechanism of calcium gating in small-conductance calcium-activated potassium channels. Nature. 1998;395:503-507.

29. Fanger CM, Ghanshani S, Logsdon NJ, et al. Calmodulin mediates calcium-dependent activation of the intermediate conductance $\mathrm{K}_{\mathrm{Ca}}$ channel, IKCa1. J Biol Chem. 1999;274:5746-5754.

30. Thomas GR, Williams MR, Sanderson J, Duncan G. The human lens possesses acetylcholine receptors that are functional throughout life. Exp Eye Res. 1997;64:849-852.

31. Grunnet M, Jespersen T, Angelo K, et al. Pharmacological modulation of SK3 channels. Neuropharmacology. 2001;40:879-887.

32. Alvarez LJ, Candia OA, Zamudio AC. Acetylcholine modulation of the short-circuit current across the rabbit lens. Exp Eye Res. 1995; 61:129-140.

33. Miller MJ, Rauer $\mathrm{H}$, Tomita $\mathrm{H}$, et al. Nuclear localization and dominant-negative suppression by a mutant SKCa3 N-terminal channel fragment identified in a patient with schizophrenia. J Biol Chem. 2001;276:27753-27756.

34. Ritsner M, Modai I, Ziv H, et al. An association of CAG repeats at the KCNN3 locus with symptom dimensions of schizophrenia. Biol Psychiatry. 2002;51:788-794.

35. Smith AA, Gavitt JA, Karmin M. Lenticular opacities induced in mice by chlorpromazine. Arch Ophthalmol. 1966;75:99-101.

36. Howard RO, McDonald CJ, Dunn CJ, Creasey WA. Experimental chlorpromazine cataracts. Invest Ophthalmol Vis Sci. 1969;8:413-421.

37. Wilson CC, Delamere NA, Paterson CA. Chlorpromazine effects upon rabbit lens water and electrolyte balance. Exp Eye Res. 1983;36:559-566.

38. Sanderson J, Gandolfi SA, Duncan G. Calmodulin antagonists induce changes in lens permeability and transparency. Curr Eye Res. 1994;13:219-224.

39. Terstappen GC, Pula G, Carignani C, Chen MX, Roncarati R. Pharmacological characterization of the human small conductance calcium-activated potassium channel hSK3 reveals sensitivity to tricyclic antidepressants and antipsychotic phenothiazines. Neuropharmacology. 2001;40:772-783.

40. Grunnet M, MacAulay N, Jorgensen NK, Jensen BS, Olesen S-P, Klærke DA. Regulation of cloned, $\mathrm{Ca}^{2+}$-activated $\mathrm{K}^{+}$channels by cell volume changes. Pflugers Arch. 2002;444:167-177.

41. Roman R, Feranchak AP, Troetsch M, et al. Molecular characterization of volume-sensitive $\mathrm{SK}_{\mathrm{Ca}}$ channels in human liver cell lines. Am J Physiol. 2002;282:G116-G122.

42. Duncan G, Bushell AR. Ion analysis of human cataractous lenses. Exp Eye Res. 1975;20:223-230. 